\title{
Mapping Density and Distribution of Urban Spaces in the City of Copenhagen
}

\author{
Gustavo RIBEIRO, The Royal Danish Academy, Architecture, Denmark \\ Aleksander NOWAK, The Royal Danish Academy, Architecture, Denmark
}

\begin{abstract}
This paper presents a study of urban density in the City of Copenhagen based on indicators of urban form, land use, socio-economic factors, and activity. Through the analysis of those indicators, this study proposes urban policy recommendations based on liveability targets set by the City of Copenhagen. The City of Copenhagen has, in the past decade, produced the "Urban Life Account" (2010 - 2019), which aims to measure and evaluate the quality of urban life in the city and the level of satisfaction with public spaces amongst its citizens. This paper evaluates the scale, distribution and resulting accessibility of urban spaces and green spaces in the City of Copenhagen in the context of the population growth in the last three decades. Through the analysis of built density and geospatial socio-economic data and data on use of urban spaces and amenities collected from digital platforms (Google Places, TripAdvisor, Flickr, and Airbnb), this study reveals significant differences in access to urban spaces and green areas and an overall pattern of centrality in density and activity intensity (measured through indirect indicators from online platforms).
\end{abstract}

\section{Keywords}

Density, Mapping, Copenhagen, social media platforms

\section{Introduction}

This paper is based on an exploratory, ongoing study, investigating the potential of aggregating different types of data on density (built density - floor area ratio [FAR], demographic density and density of activities) to qualify urban policy with a focus on liveability in the City of Copenhagen. The study of density presented in this paper, and the analysis of its effects on liveability, is premised on a projected population growth of 100,000 inhabitants in the next decade as a key point of departure for urban policy making and planning in Copenhagen (City of Copenhagen - Financial Administration, 2019). In connection with this study, our dialogue partners from the City of Copenhagen have described the challenge of densification as a "fight for space", as the city becomes denser, and more people (both citizens and visitors) and amenities must share the city's urban spaces.

This study introduces an analysis of data on built density and geospatial socio-economic data, supplemented with data on use of urban spaces and amenities collected from digital platforms, namely Flickr, Airbnb, Google Places and TripAdvisor. In addition, Sentinel-2 Satellite imagery was used to generate NDVI based mappings of Copenhagen and further qualify an analysis of green spaces.

The maps were produced by the Catalan urban planning agency $300.000 \mathrm{~km} / \mathrm{s}$ in dialogue with the authors. Approximately one hundred maps were produced, and it is expected that further analysis will be conducted on the data used to generate these maps. 
The aim of the present study is to provide a more nuanced discussion on density and densification and their potential impact on the use of urban spaces and liveability (as framed by the City of Copenhagen's Urban Life Account) and to explore the potential of using data-based mapping methods to inform urban policy. This paper does not argue for densification as an urban strategy, nor does it presuppose that a compact cities approach should be a condition for sustainability - an argument that has been contested by authors such as Neuman (2005).

Following this introduction, this paper includes a Background section with a discussion of state-of-the-art scholarship in the fields of density mapping and liveability studies and a presentation of the City of Copenhagen's policies on liveability. The Methodology section presents a description and discussion of parameters and considerations concerning data gathering, aggregation and analysis. This is followed by a section presenting Results of the study, a Discussion, and a Conclusion.

\section{Background}

\subsection{Density Studies}

There has been in recent years an increased focus on the study of density in connection with analyses of urban form and urban structure. Krehl et al (2016) propose that urban density ought to be considered a key concept in studies of urban spatial structures and in particular explore possibilities of using geodata to analyse density patterns in urban areas (Krehl et al., 2016, p. 3). Studies on the impact of urban density for people's quality of life and health have come further into focus in the light of the current COVID-19 pandemic. Teller, J. (2021) presents a review and analysis of scientific articles on the influence of urban density on the diffusion of Covid-19 (Teller, 2021) and shows that the correlation between those two variables is disputed and that such an analysis should be framed in the context of a broader discussion including the health benefits of compact cities, such as walkability (Wang and Yang, 2019) (Zhou et al., 2020). Under the current COVID-19 pandemic, the use of parks in the City of Copenhagen has increased significantly (Google, 2021) further bringing into focus a discussion of intensification of use of urban spaces. ${ }^{1}$

Several studies have specifically included data from online platforms to analyse density and spatial distribution of human activities. Chen, T., et al (2019) have articulated a methodology to study urban density in Hong Kong, which involves tracking people's use of social media to study dynamic distribution of human activities and behaviour and high-density urban areas, notably through the analysis of Facebook check-ins. The study reveals a "node-like" pattern of high-density clusters distributed throughout the city of Hong Kong. The potential of such an approach to provide a more nuanced analysis not only of demographic (residential) density or built density (FAR), but also recreative activities (based on the analysis of data gathered from online platforms) is particularly explored in the present paper.

Roth et al. (2011) have studied urban structure through an analysis of urban movements in London, mapped on the basis of Oyster card database, showing mobility flows at different scales, and revealing a polycentric hierarchical structure with centres and sub-centres (Roth et al., 2011).

Studies investigating the impact of densification on the quality of green spaces such as Haaland \& van den Bosch (2015) have shown how urban densification processes can be detrimental to urban green space (Haaland and van den Bosch, 2015).

\footnotetext{
${ }^{1}$ COVID-19 Community Mobility Report, Capital Region of Denmark May 27, 2021

https://www.gstatic.com/covid19/mobility/2021-05-27_DK_Capital_Region_of_Denmark_Mobility_Report_en.pdf
} 
In their comprehensive analysis of development of residential areas in Denmark, Samuelsson et al (2020) have shown that a number of residential environments in Denmark have undergone simultaneous densification and greening since the mid-1990s (Samuelsson et al., 2020).

\subsection{Liveability Studies}

Scholarship on liveability draws on the pioneering work of Gehl (Gehl, Jan, 1971) (Gehl, 2001) (Gehl and Svarre, 2013). Gehl extensively documented and discussed the relationship between design of urban spaces and urban life in Copenhagen as well as other cities in Denmark and internationally (Gehl, 2010).

Recent studies of urban spaces in Copenhagen include Peschardt et al (2012), who have shown the importance of small public urban green spaces (SPUGS) for social interaction and mental restoration (Peschardt et al., 2012, p. 243).

\subsection{Copenhagen - A Metropolis for People}

Liveability has played a central role in urban policies, strategies and plans for the City of Copenhagen, notably in the last 15 years. Liveability is a central strategic framing narrative informing urban policy in the City of Copenhagen and it may be described as an emergent strategic concept (Healey, 2007, p. 183). The City of Copenhagen's Planning Statement 2007 highlighted the key role of public spaces for urban live (City of Copenhagen, The Technical and Environmental Admnistration, 2007) and the Planning Strategy 2007 underlined the role of the city's public spaces as settings for experience of culture, urban life and physical activities (City of Copenhagen, 2007).

Copenhagen's prominent placement in several international liveability (and sustainability) ranking indexes has also played a role in framing a narrative of Copenhagen as a liveable city. Copenhagen topped Monocle's Quality of Life Index for the first time in 2008 and again in 2013, 2014 and 2021.

Simpson et al (2018) have questioned the relevance of a narrow viewing of Copenhagen through the lenses of city-ranking indexes (Simpson, D. et al., 2018), but effectively, Copenhagen's prominent position has become part of the political discourse (Lauridsen, M. A., 2014), (CopCap, 2021).

The City of Copenhagen launched in 2009 the urban strategy "A Metropolis for People" - produced in collaboration with Gehl Architects - which articulated at vision of Copenhagen as "the world's most liveable city". A Metropolis for People contains specific targets for the level of satisfaction amongst Copenhageners with the city's urban life (City of Copenhagen - The Technical and Environmental Admnistration, Gehl Architects, 2009). The achievement of these goals has been assessed in the "Urban Life Account" published between 2010 and 2019 on a yearly basis.

Of special interest for the analysis contained in this paper is the fact that the Urban Life Account 2019 presents marked differences in the level of satisfaction with urban life between respondents from centrally located neighbourhoods ( $N \varnothing r r e b r o$ ) and residents from peripheral neighbourhoods (Bronshøj) (City of Copenhagen - The Financial Admnistration, 2019, p. 4)

\subsection{Demographic Growth and Densification in Copenhagen}

Population growth is a key driver of urban policy in the City of Copenhagen, both in terms of provision of sufficient and adequate housing, of amenities - such as schools, day care, nursing homes, and culture and leisure facilities - and of green spaces (City of Copenhagen - Financial Administration, 2019, pp. 13, $15,17,20)$.

The population of Copenhagen Municipality is projected to grow by 100,000 inhabitants by 2031 (City of Copenhagen - Financial Administration, 2019, p. 5) increasing the total number of inhabitants in 2031 to 725,000 from approx. 467,000 in 1990 (the year the city's population hit its lowest level in 100 years). 
The City of Copenhagen's policies for urban spaces are based on this projected growth and the effects of increased density for urban life in the city, notably in view of securing mixed in diverse neighbourhoods and promoting "good urban life" (City of Copenhagen - Financial Administration, 2019, p. 13).

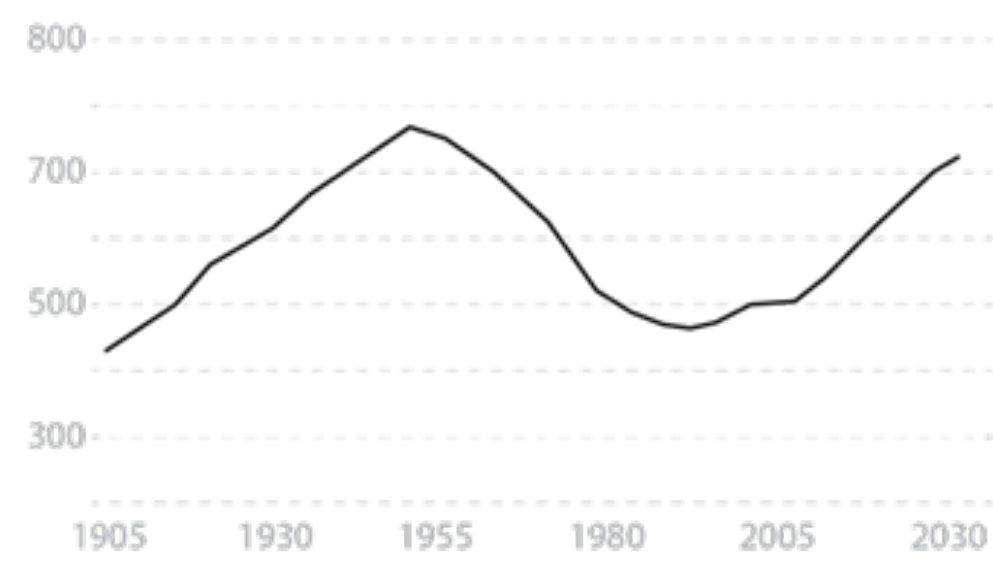

Figure 1: Population Growth in Copenhagen. Source: Statistics Denmark and City of Copenhagen (Copenhagen Municipal Plan 2019)

The Copenhagen Municipal Plan 2019 establishes specific goals for green spaces (which are also included in the Urban Life Account) and specifies that Copenhageners should have easy access to attractive green areas that are close people's residences and working places. More concretely, it includes a guideline that there ought to be no more than 300 meters in walking distance from the city's housing to recreational areas (parks, pocket parks, green urban spaces, amongst others), (City of Copenhagen, 2019, p.12).

\section{Methodology}

Geolocated data generated by users of online platforms as a by-product of their online presence and activity have been used in this study as proxy indicators for intensity of activities. In the present study the data sourced from four online platforms (Google Places, TripAdvisor, Flickr, and Airbnb) were used to map variables such as density of commercial activities (Google Places), density of restaurants, number of reviews and ratings (TripAdvisor), spatial distribution of photographs uploaded by users (Flickr) and location, ownership and rating of accommodation offered to travellers (Airbnb).

We have combined data from those four online platforms on spatial distribution and intensity of activities with data on demographic density, built density and distribution of green areas (green parks, green courtyards, trees, and other vegetation) in view of producing a more detailed basis for qualifying a discussion on liveability.

Geolocated data on people's online activity are included in this study to show the potential intensity of use and potential pressure the analysed urban spaces are under to accommodate surge in use - a pressure which is likely to increase with further demographic growth, surge in the number of visitors and consequent densification of urban areas within the Municipality of Copenhagen.

The data from online platforms - in combination with data on demography, urban density, and greenery inform a discussion of overall spatial patterns (such as centrality) as well an indication of which urban areas present a lower provision of green spaces. 
The following methodological limitations of this study may be highlighted: (a) the population of users of the four online platforms represents a limited segment of users of urban spaces of the city ${ }^{2}$; (b) as the data are extracted on a particular date, it represents a snapshot of a changing condition. In the case of Flickr, one type of data refers to a cumulative set of photographs uploaded on the platform since it was launched on February $10^{\text {th }}, 2004$. In the case of Airbnb, a dataset referred to properties listed on the site at the date the data were gathered. These limitations can arguably be mitigated by the richness of the datasets, and the fact that the analysis combines the data from the four online platforms and data on demographic and built density.

Publicly accessible registers consulted in this study include opendata.dk [https://www.opendata.dk/], Kortforsyningen [https://kortforsyningen.dk/], Municipal Plan 2019 map database [https://kp19.kk.dk/kortportal]. This was supplemented by more detailed and up-to-date datasets provided by the City of Copenhagen including datasets on trees, courtyard (location and presence of greenery), location of green spaces (according to the classification by the City of Copenhagen).

Data from the four online platforms and from the register listed above were used to produce six types of maps:

1. Datapoint Maps - individual data points showing for instance the location of a tree or restaurant,

2. Heat Maps - showing intensity of concentration of data points

3. Mashup Maps - combining data from Datapoint Maps and Heat Maps

4. $200 \mathrm{~m} \times 200 \mathrm{~m}$ Grid Maps - data aggregated on a $200 \mathrm{~m} \times 200 \mathrm{~m}$ grid

5. $100 \mathrm{~m} \times 100 \mathrm{~m}$ Grid Maps - data aggregated on a $100 \mathrm{~m} \times 100 \mathrm{~m}$ grid

6. Urban Structure Maps - showing structure of road infrastructure, urban spaces, urban blocks, and courtyards

The data were processed in qGIS and Python except for NDVI.

Data from Copenhagen Municipal plan structure maps [public spaces, streets, and blocks] [https://kp19.kk.dk/kortportal], were used not only as an underlay for the other maps used in this study, but were also aggregated into a grid showing spatial distribution of density and thus providing a basis for comparison between different areas and their public spaces.

Sentinel-2 Satellite imagery was used to generate NDVI based mappings of Copenhagen in addition to data on the spatial distribution of trees and greenery. Satellite imagery allowed for generating a consistent and uniform image of urban greenery and a detailed analysis of distribution of vegetation and its intensity. NDVI data can be turned into statistical data for further analysis to inform the level of present distribution, historical development of the green elements, or their relation to urban densification.

\section{Results}

\subsection{Map Analysis}

Approximately one hundred maps were produced and edited in three rounds. In this section and in the following section we present an analysis of selected maps. The maps referred to in this the present analysis are listed on Table 1.

\footnotetext{
${ }^{2}$ Many users of Flickr have gradually migrated to Instagram, which was launched in October 2010.
} 


\begin{tabular}{|c|c|c|c|}
\hline \# & Title & Data source & Description \\
\hline 1 & Commercial activities & Google places & Density of commercial activity through the available points in Google places data \\
\hline 3 & $\begin{array}{l}\text { Commercial activities- } \\
\text { heatmap }\end{array}$ & Google places & Density of commercial activity through a heatmap of the points extracted of Google places \\
\hline 6 & Restaurants - Mash-up & TripAdvisor & Density of restaurants through the points extracted from the Tripadvisor platform \\
\hline 7 & Attractiveness & Flickr & Density of attractiveness - points of photos uploaded on Flickr \\
\hline 8 & Attractiviness - heatmap & Flickr & Density of attractiveness - heatmap of photos on Flickr \\
\hline 10 & Density of sleeping tourists & Airbnb & Density of sleeping tourists - points of Airbnb apartments extracted from the platform \\
\hline 12 & $\begin{array}{l}\text { Dens. of sleeping tourists- } \\
\text { mash-up }\end{array}$ & Airbnb & Density of sleeping tourists - heatmap of Airbnb points \\
\hline 13 & Most density of dynamic data & Various & Data from Tripadvisor, Google Places, Flickr, Airbnb - aggregation \\
\hline 18 & Density of restaurants & TripAdvisor & Density of restaurants - number of restaurants registered on TripAdvisor ( $n$ ) aggregated to a grid \\
\hline 21 & Most visited & TripAdvisor & Number of TripAdvisor reviews (pink, num_reviews) and TripAdvisor rank, rated by users (blue, rank_raw) \\
\hline 25 & Number of photos & Flickr & Number of photos on Flickr located in the city of Copenhagen (yellow, count) aggregated to a grid \\
\hline 43 & Most visited apartments & Airbnb & Representation of the most visited appartments - number of reviews on Airbnb (blue, reviews_total) \\
\hline 65 & Urban fabric - built density & Opendata.dk / CPH M. & Representation of the built footprint and blocks hierachy from the City of Copenhagen database \\
\hline 66 & Public space - streets & Opendata.dk / CPH M. & Street shape and public spaces as an intersection of the built footprint and blocks hierachy \\
\hline 67 & Major green spaces & Opendata.dk / CPH M. & Major green spaces \\
\hline 68 & Courtyards & CPH Municipality & Green courtyards \\
\hline 69 & Vegetation NDVI & Sentinetl-2 & Nature Density Vegetation Index (Sentinel satellite network) \\
\hline 70 & Trees & CPH Municipality & Location of trees from the municipal databases \\
\hline 71 & Green infrastructure & CPH Municipality & Superimposition of main public and green spaces, trees and NDVI index \\
\hline 73 & Built density & CPH Municipality & Built density in a $100 \times 100$ grid calculated from the buildings footprint \\
\hline 74 & Street density & CPH Municipality & Total surface of streets aggregated to a $100 \times 100$ grid \\
\hline 75 & Density of green courtyards & CPH Municipality & Green courtyards aggregated (grid)| \\
\hline 76 & FAR vs courtyards & CPH Municipality & Superimpositon of the sum of the built surface and the public spaces total surface - $100 \times 100$ grid \\
\hline 78 & Trees $100 \times 100$ & CPH Municipality & Total amount of trees aggregated to a $100 \times 100$ grid \\
\hline 79 & Trees Radius Height NDVI & Sentinel-2 & Average radius of trees (age indicator) \& average height aggregated to a $100 \times 100$ grid \\
\hline 81 & Trees + Veg. + Courtyards & CPH Municipality & Total srf. of public spaces, the total amount of trees and the average index of vegetation - $100 \times 100$ grid \\
\hline 88 & The surrounding built density & CPH Municipality & Total built surface (footpint) of the surroundings aggregated to the grid in public spaces \\
\hline 91 & $\begin{array}{l}\text { Density of activ. in leisure } \\
\text { facil. }\end{array}$ & $\begin{array}{l}\text { TripAdvisor } \\
\text { CPH Municipality }\end{array}$ & Total amount of restaurants in relation to reviews (both of the surroundings) \\
\hline 98 & Inhabited fabric & CPH Municipality & Populated areas in the city according to cadaster data \\
\hline 100 & FAR (floor area ratio) & CPH Municipality & Plot occupation according to cadaster data \\
\hline 103 & Pop. density / plot surface & CPH Municipality & Population per plot surface according to cadaster data \\
\hline
\end{tabular}

Table 1: List of Maps

\subsection{Distribution of Green Spaces}

As previously mentioned, this study involved the analysis of four levels of data concerning green spaces and trees - namely (1) NDVI; (2) Tree database (location, radius and height of individual trees), (3) Green spaces (as registered by the City of Copenhagen); (4) Courtyards (as designated in the Copenhagen Municipal Plan 2019) - this analysis aimed to provide a more detailed basis for assessing proximity from residential areas to green spaces and identify neighbourhoods which have more limited access to green spaces and greenery. Ten maps were analysed through different combinations of these four levels of data and through different forms of aggregation/visualization $(200 \mathrm{~m} \times 200 \mathrm{~m}$ grid, datapoints, urban structure maps). The maps $(67,68,69,70,71,75,76,78,79,81)$ described on Table 1 show how greenery seen through the lenses of these four levels of data is very unevenly distributed throughout the city. Each dataset presents a different pattern of distribution.

Map 79, which aggregates three levels of data on greenery (NDVI, tree height and tree radius) on a 100m $x 100 \mathrm{~m}$ grid, shows the spatial distribution of all green elements in the city and reveals areas of lower density of greenery (measured according to those three variables). The neighbourhoods of the Medieval City, Inner Vesterbro, and Central Amager stand out in this map as areas of lower density of greenery.

Map 80 showing the distribution of individual trees in combination with NDVI index reveals markedly higher concentration of greenery in peripheral areas. The higher concentrations of trees in the central area coincides with the parks in the belt formally occupied by the ramparts of the Medieval City, Rosenborg 
Castle Gardens, and the Botanic Gardens. Maps 81,89 and 90 further illustrated this uneven pattern of distribution of green areas in the city.

Green semi-private spaces, shown on Map 68, constitute a significant element of greenery in the city, even though most of these courtyards are only accessible to residents of the block surrounding them. The courtyards in the Medieval City are notably devoid of greenery.

\subsection{Density and Centrality}

The Fingerplan (1947 - 2017), which has guided the spatial development of Copenhagen Metropolitan Region as a strategic spatial plan since 1947, and which gained statutory status as a structure plan in 2007 (Danish Business Authority, 2017) has laid the basis for a monocentric development, which amongst others has led to an unbalanced development in housing prices (in the privately owned and private rental sectors) from the centre (palm of the hand), to the periphery (fingers). Housing prices in centrally located areas, which cover most of the Municipality of Copenhagen, present the most accelerated increase in prices (Liliegreen, C., 2018). This centrality is well documented in the extensive studies carried out by The Knowledge Centre for Housing (https://www.bvc.dk).

A pattern of centrality is shown in the Copenhagen's radial urban structure (Map 66), building density (Map 65 and Map 73) and demographic density (Map 103). In addition, such pattern of centrality is manifested in the maps based on data from the four online platforms - Google Places, TripAdvisor, Flickr, and Airbnb.

Map 1 shows a concentration of commercial establishments in the Medieval City and Inner Vesterbro spreading radially along main streets, such as Østerbrogade, Vesterbrogade, Nørrebrogade and Amagerbrogade. This centrality is also clearly visible in the heat map (Map 3).

Map 6 and Map 18 both show the distribution of restaurants (Tripadvisor) also revealing a concentrated spatial distribution of restaurants in the Medieval City and Inner Vesterbro.

Map 7 (photographs uploaded on Flickr) and Map 8 (most viewed photographs on Flickr) both reveal a centralized spatial distribution of photographs, with the Medieval City, Inner Vesterbro, Frederiksstaden and Langelinje showing the greatest concentrations. In addition, these maps show the presence of points of concentration in Ørestad on the location of contemporary iconic architectural works by the architecture firm BIG (www.big.dk), namely VM Houses, The Mountain and 8Tallet. New points of concentration in those maps also correspond to the location of international events such as the rock festival Copenhell and the street food market on Refshaleøen. Map 25 shows the distribution of all photographs uploaded on Flickr aggregated on a $200 \mathrm{~m} \times 200 \mathrm{~m}$ grid, where this centralized pattern of spatial distribution is clearly visible.

Map 10 and Map 12 show a higher concentration of Airbnb accommodations in the central areas of the city. A similar pattern has been identified by authors such as Lagonigro et al (2020) In their study of Barcelona demonstrating that neighbourhoods farther away from the centre present a lower ratio of Airbnb accommodations (Lagonigro et al., 2020). On the other hand, those maps show Airbnb accommodations on offer in peripheral neighbourhoods, though in significant lower number than in central areas of the city.

Map 13 combines data from the four online and shows areas of concentration of activities corresponding to data from each of the platforms. Those four layers partially overlap and reveal a more nuanced picture of a pattern of centrality, with areas of concentration derived from data on Airbnb accommodation showing a pattern which extends farther out into neighbourhoods around the city centre. The layer corresponding to data from Flickr shows both a concentration in the city centre (Medieval City and Inner Vesterbro), but also more peripheral points of concentration corresponding to the location of iconic architectural works and international cultural events. The layers based on data from TripAdvisor and Google Places show a concentration in the Medieval City and in Inner Vesterbro. 


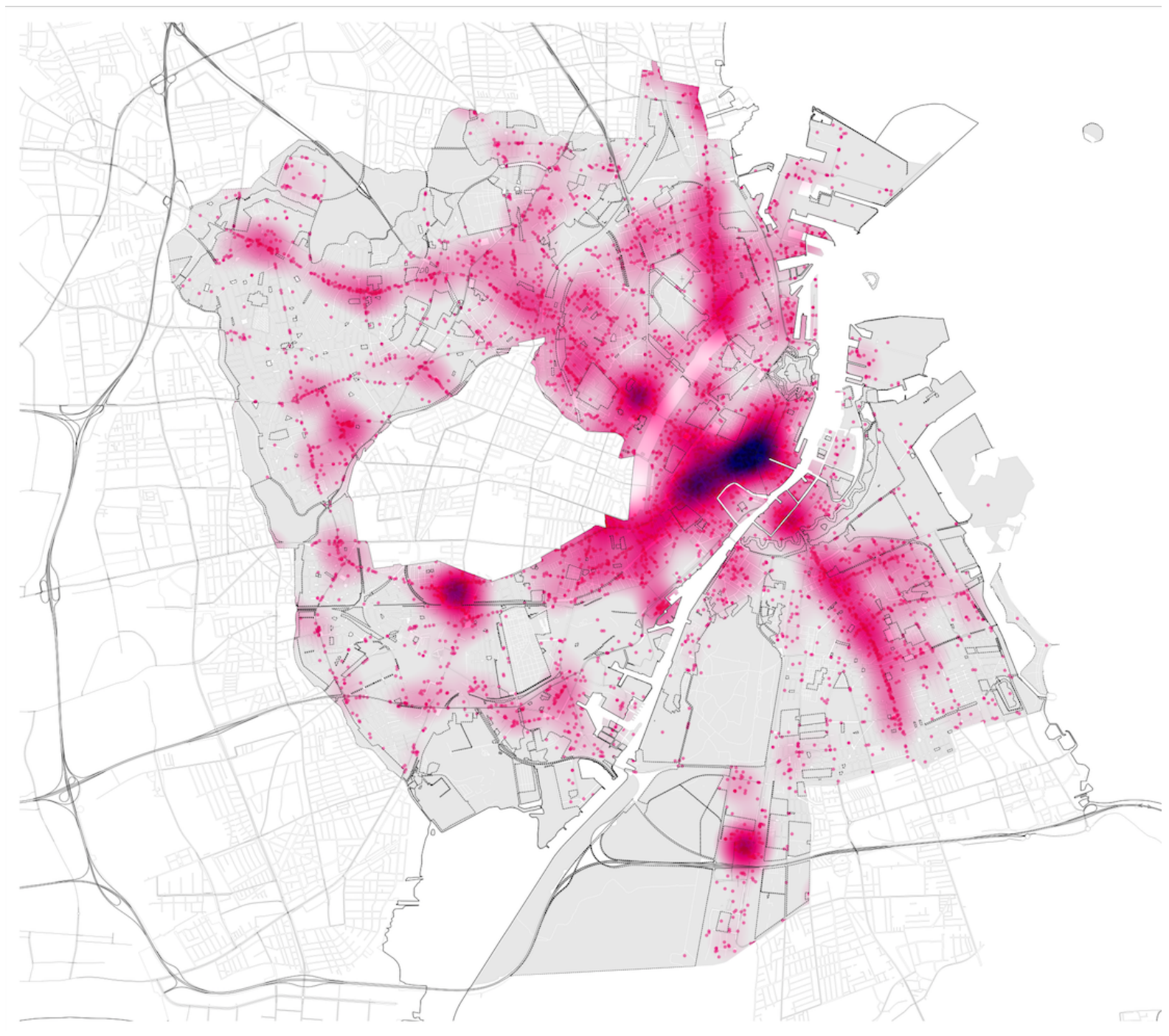

Figure 2 Commercial Activity Heat Map - Map 3 (Source: Google Places) 


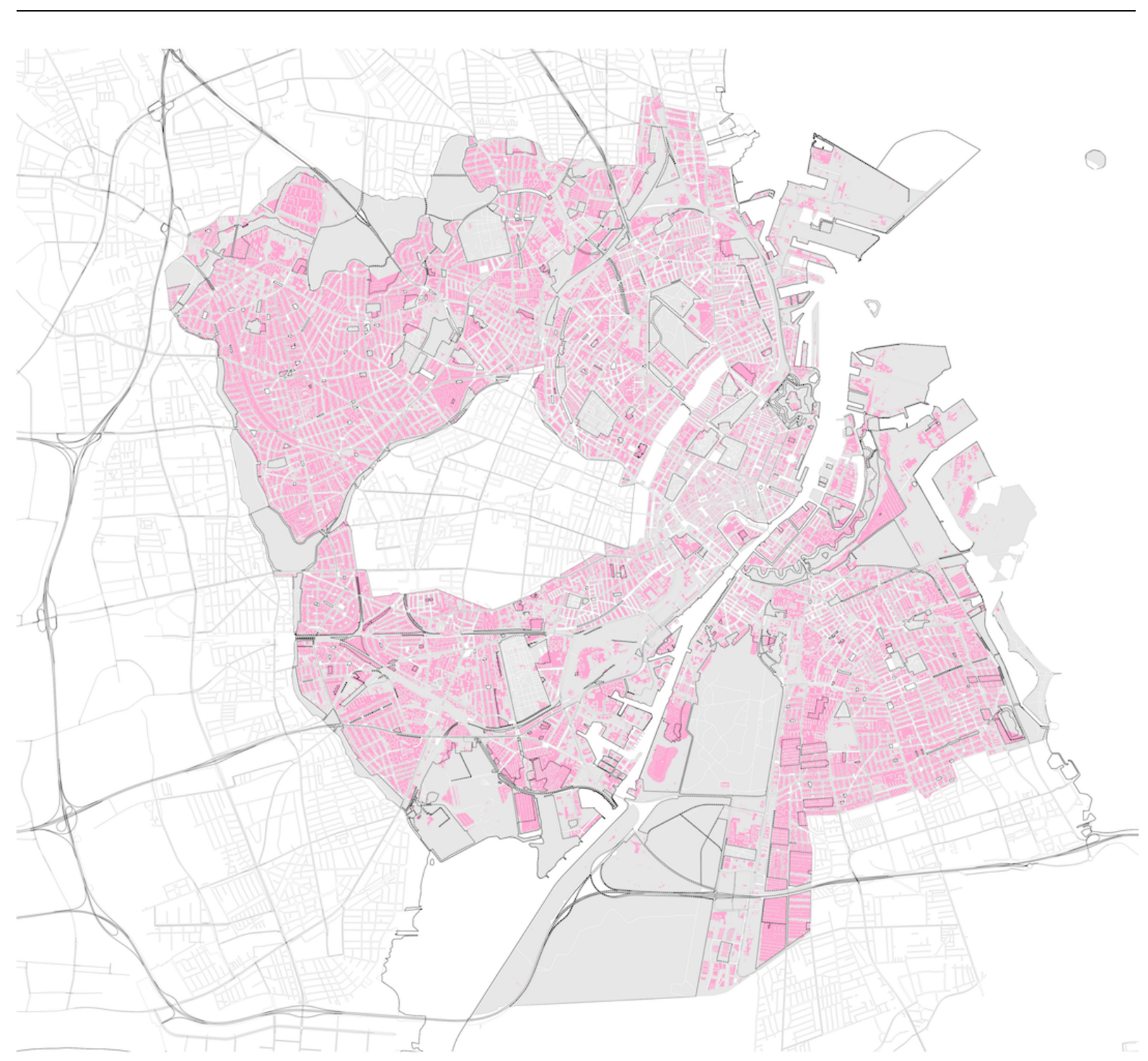

Figure 3: Green Courtyards - Map 68 (Source: City of Copenhagen) 


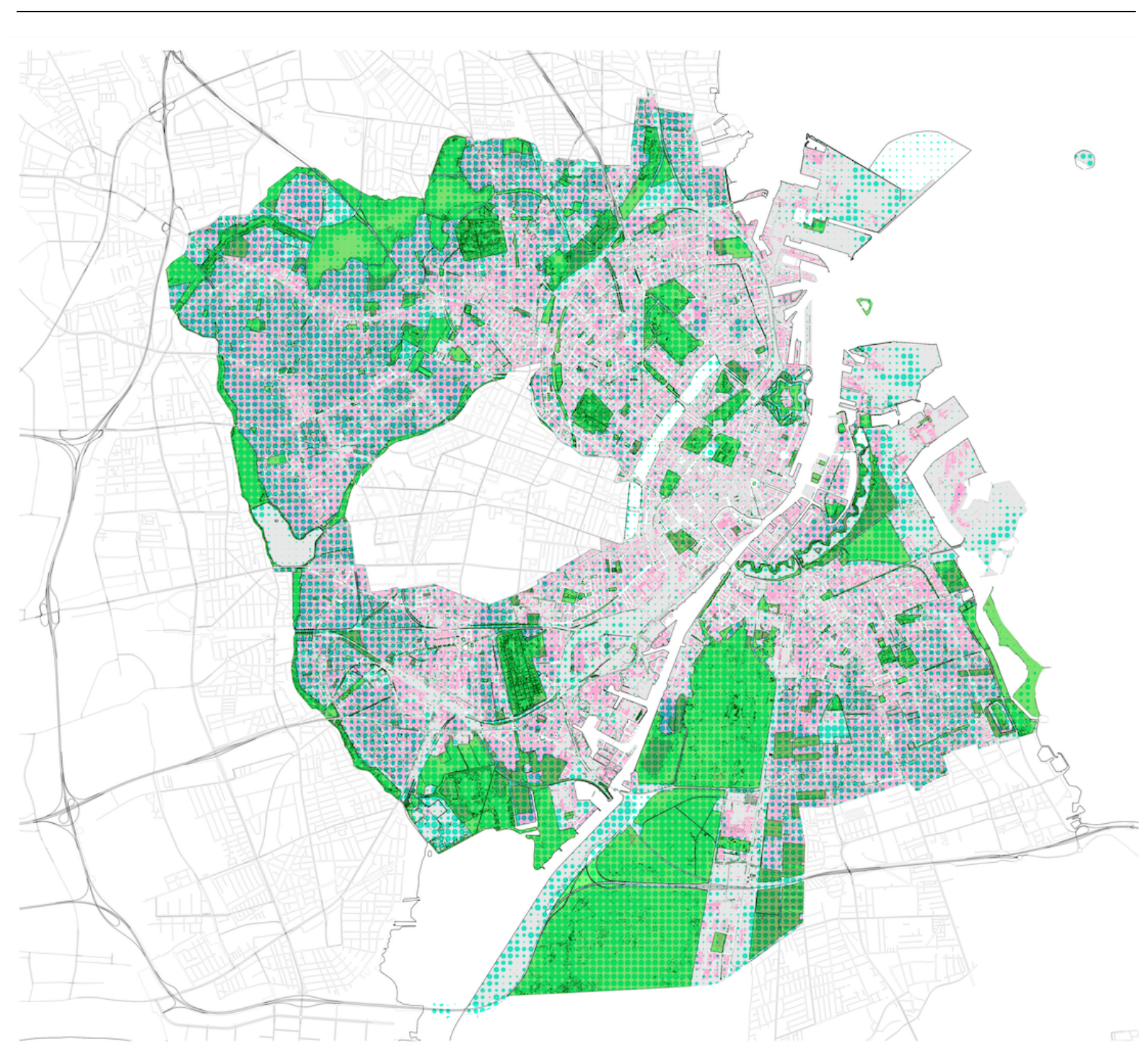

Figure 4: Green Infrastructure - Map 71 (Source: Multiple) 


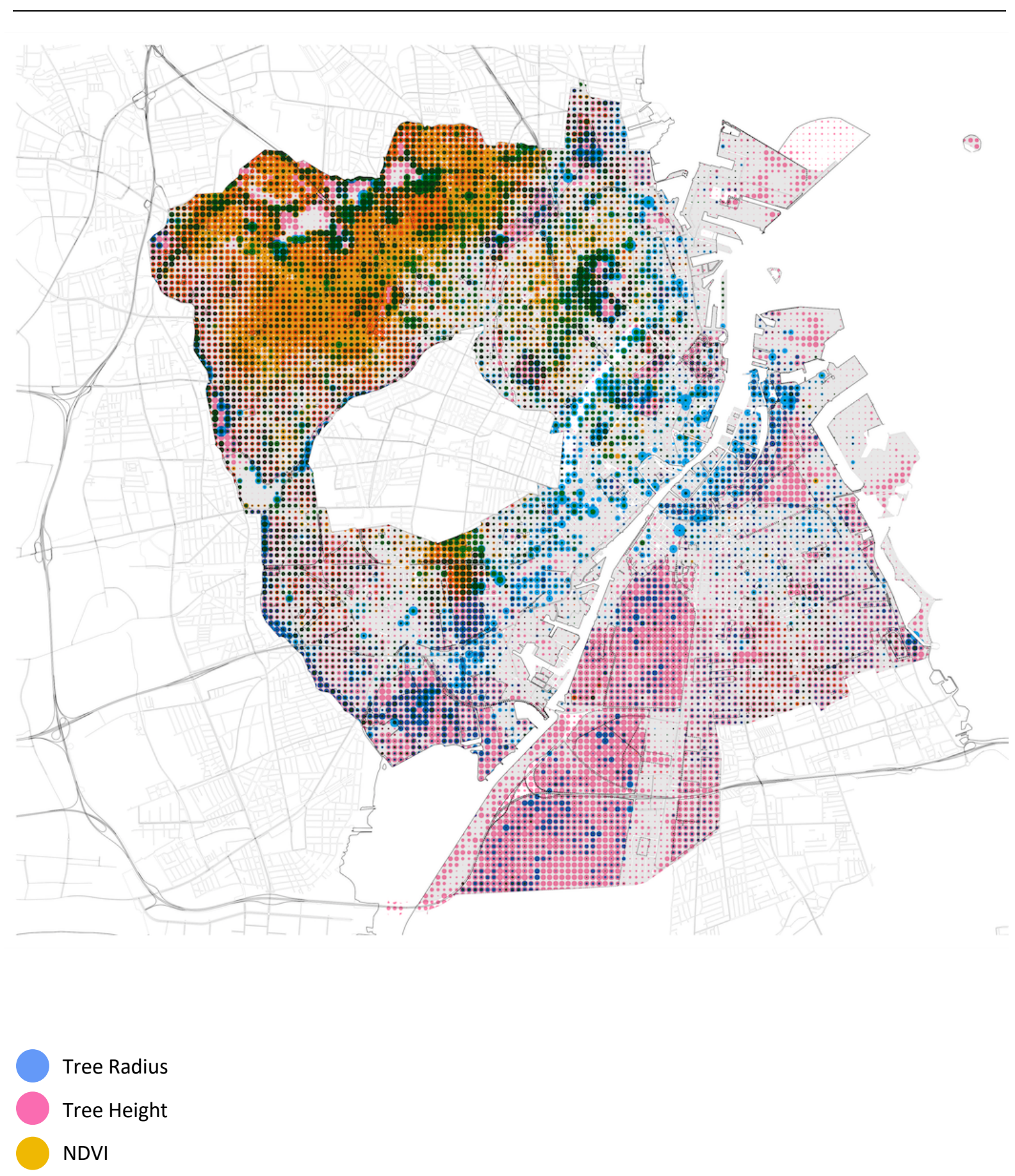

Figure 5: Trees - Radius, Height, NDVI - Map 79 - (Source: Multiple) 


\section{Discussion}

The analysis of maps showing the distribution of greenery indicates that the Medieval City and Inner Vesterbro - the neighbourhoods that presented the highest built density (FAR) - are also the areas where access to greenery is lowest, compared to other neighbourhoods - Map 73.

In the case of Medieval City, this lower incidence of greenery, shown in the maps as lower NDVI values (Map 69), lower number of trees (Map 70) and smaller and built-up courtyards with reduced space for greenery (Map 68), is compensated by the ring of parks around it in the location of the former medieval ramparts.

In the case of Inner Vesterbro, lower NDVI values are also clearly visible (Map 69). Map 71, which aggregates all four types of data used in this study to analyse conditions of access to green spaces in different neighbourhoods of Copenhagen - namely NDVI index, location of individual trees, larger green spaces following the classification by the City of Copenhagen and green courtyards - also show a deficiency of green spaces compared to other neighbourhoods, notably in the immediate periphery of the Municipality of Copenhagen.

An analysis of the correlation of density of restaurants (and number of reviews) with major green spaces (following the classification by the City of Copenhagen) is shown on Map 91. The concentration of those restaurants as well as other amenities can contribute to identifying areas where investment in recreational and green spaces or in their perimeter areas could be prioritized.

NDVI data revealed aspects concerning the spatial distribution of greenery that are not present in the maps of green spaces in the Municipal Plan 2019 (Map 67). More specifically - an overlay of NDVI maps and tree sizes and their distribution reveals the importance of low vegetation and shrubs. NDVI analysis showed the intensity of greenery on private plots, in courtyards and in private gardens, thus providing a more detailed picture of the location of greenery in the city.

Tripadvisor data can be used to supplement data gathered from the business register (CVR database) https://datacvr.virk.dk/data/). In addition to information on location of restaurants, it provides data on number of reviews per restaurants.

The analysis of Airbnb data has shown that the neighbourhoods of Nørrebro and Vesterbro include a significant number of traveller accommodation and supplementing hotel accommodation which concentrated in the city centre (Map 43).

\section{Conclusion}

The analysis of data from online platforms (Airbnb, Flickr, TripAdvisor and Google Places) has shown a strong pattern of centrality, notably in maps of location of restaurants (TripAdvisor, Google Places) and number of reviews (TripAdvisor), but it has also revealed a more complex territorial distribution of activities, with a concentration in the Medieval City expanding to include the neighbourhoods of Nørrebro, Vesterbro and Amager, as in the case of the location of Airbnb accommodation, and with the appearance of new satellites of concentration, as shown by the location of photographs (Flickr).

The analysis of greenery and green spaces, presented in this paper, aimed to qualify a broader discussion as well as initiatives concerning the improvement of liveability through development of policy or through concrete projects for upgrading of green spaces, notably in the context of the Copenhagen Municipal guideline of a maximum of $\mathbf{3 0 0}$ meters in walking distance from the city's housing to a recreational area.

Mapping the spatial distribution of green elements through a combination of NDVI data and tree data (location, radius, height), supplemented with data on green courtyards has provided a more comprehensive and nuanced analysis. The correlation between the pattern of spatial distribution shown in 
such analysis with users' experiences of greenery in the city and their perceived accessibility to green spaces is an issue that needs to be further investigated, in view of a more detailed assessment of the applicability of the present approach in the development of urban liveability policies.

The spatial analysis and mapping presented in this study has the potential of informing policy making on liveability in the City of Copenhagen. Specifically, the mapping of greenery combining the four abovementioned layers of data, can inform a more detailed development of targets and assessment of liveability in connection with the Urban Life Account. It can be used for instance, in the design of the questionnaires, used in connection with the Urban Life Account, that specifically address neighbourhoods that present low accessibility to green areas as shown in this study.

It is important to emphasize that we do not propose that the present study can be used in isolation in the development of liveability policy and planning tools, but rather, it needs to be coupled with qualitative methods that include the assessment of perceived spatial variables that affect people's use of urban spaces.

\section{Acknowledgments}

The present study is based on dialogue and collaboration between the Royal Danish Academy and the City of Copenhagen. Our collaborators in the City of Copenhagen have provided detailed built density and geospatial socio-economic data and have engaged in a constructive dialogue about central issues connected to densification in the City of Copenhagen.

The Catalan urban planning agency $300.000 \mathrm{~km} / \mathrm{s}$ (https://300000kms.net), through the work of Mar Santamaria and Pablo Martinez, has contributed with data gathering, aggregation of data and production of all maps referred to in this paper as well as map analysis.

\section{References}

Bamford, G., (2009). 'Urban Form and Housing Density, Australian Cities and European Models: Copenhagen and Stockholm Reconsidered.' Urban Policy Research 27, 337-356. Available at: https://doi.org/10.1080/08111140903108572 (Accessed: 15 September 2021)

Capital Region of Denmark (2021) COVID-19 Community Mobility Report, C May 27, 2021. Available at: https://www.gstatic.com/covid19/mobility/2021-05-

27_DK_Capital_Region_of_Denmark_Mobility_Report_en.pdf (Accessed: 15 September 2021).

City of Copenhagen - Financial Administration (2019) Copenhagen Municipal Plan 2019 | Københavns Kommuneplan 2019. Available at: https://www.kp19.kk.dk/sites/default/files/202103/Kommuneplan\%2019\%20Engelsk\%2003.pdf (Accessed: 15 September 2021).

City of Copenhagen - Financial Administration (2007) Den Tænkende Storby - Planredegørelse 2007. Copenhagen. Available at: https://www.kk.dk/sites/default/files/edoc_old_format/Teknik\%20og\%20Miljoeudvalget/24-10-2007\%2015.00.00/Dagsorden/22-10-

2007\%2010.37.30/Strategi\%202007\%202.PDF (Accessed: 15 September 2021).

City of Copenhagen - The Technical and Environmental Administration (2019) Bylivsregnskab 2019. Copenhagen. Available at: https://kk.sites.itera.dk/apps/kk_pub2/index.asp?mode=detalje\&id=2043 (Accessed: 15 September 2021).

City of Copenhagen - The Financial Administration (2007) Den Tænkende Storby - Kommuneplanstrategi 2007. Copenhagen. Available at:

https://www.kk.dk/sites/default/files/edoc_old_format/Amager\%20Øst\%20Lokaludvalg/13-03- 
2008\%2018.30.00/Dagsorden/07-03-

2008\%2010.38.36/07\%2001\%20Kommunalplanstrategi\%202007.PDF. (Accessed: 15 September 2021).

City of Copenhagen - The Technical and Environmental Administration (2015) Co-Create Copenhagen. Copenhagen. Available at: https://urbandevelopmentcph.kk.dk/artikel/co-create-copenhagen (Accessed: 15 September 2021).

City of Copenhagen - The Technical and Environmental Administration, Gehl Architects (2009) A Metropolis for People. Copenhagen. Available at: https://gehlpeople.com/story-article/ametropolis-for-people/ (Accessed: 15 September 2021).

CopCap, 2021. Life in Copenhagen. URL https://www.copcap.com/living-and-working/life-in-copenhagen (Accessed: 15 September 2021).

Danish Business Authority, 2017. Fingerplanen 2017. Available at: https://planinfo.erhvervsstyrelsen.dk/sites/default/files/media/fingerplan_2017_26072017.pdf (Accessed: 15 September 2021)

Gehl, J. (2010) Cities for people. Island Press: Washington, DC.

Gehl, J. (2001) Life between buildings: using public space. Arkitektens Forlag: Copenhagen.

Gehl, J., Svarre, B. (2013) Bylivsstudier: studier af samspillet mellem byens form og byens liv. Bogværket: Copenhagen

Gehl, J. (1971) Livet Mellem Husene. Arkitektens Forlag: Copenhagen.

Haaland, C., van den Bosch, C.K. (2015) 'Challenges and strategies for urban green-space planning in cities undergoing densification: A review.' Urban Forestry \& Urban Greening 14, 760-771. Available at: https://doi.org/10.1016/j.ufug.2015.07.009 (Accessed: 15 September 2021)

Healey, P. (2007) Urban Complexity and Spatial Strategies: Towards a Relational Planning for Our Times. Routledge: London and New York.

Krehl, A., Siedentop, S., Taubenböck, H., Wurm, M. (2016) A Comprehensive View on Urban Spatial Structure: Urban Density Patterns of German City Regions. ISPRS International Journal of GeoInformation 5, 76. Available at: https://doi.org/10.3390/ijgi5060076 (Accessed: 15 September 2021)

Lagonigro, R., Martori, J.C., Apparicio, P. (2020) Understanding Airbnb spatial distribution in a southern European city: The case of Barcelona. Appl. Geogr. 115, 102136. Available at: https://doi.org/10.1016/j.apgeog.2019.102136 (Accessed: 15 September 2021)

Lauridsen, M. A., 2014. København kåret til verdens bedste by - igen. Berlingske Nyhedsbureau.

Liliegreen, C. (2018) 'Et kritisk blik på Fingerplanen.' Byplannyt 16. årgang, 19. Available at: https://www.byplanlab.dk/sites/default/files/201904/ByplanNyt1_2018_web.pdf?0.5691171488724649. (Accessed: 15 September 2021)

Neuman, M. (2005) 'The Compact City Fallacy.' Journal of Planning Education and Research vol. 25 Issue 1. Available at: https://doi.org/10.1177/0739456X04270466 (Accessed: 15 September 2021)

Peschardt, K., Schipperijn, J., Stigsdotter, U. (2012) 'Use of small public urban green spaces (SPUGS).' Urban Forestry \& Urban Greening 11, 235-244. Available at: https://doi.org/10.1016/j.ufug.2012.04.002 (Accessed: 15 September 2021) 
Roth, C., Kang, S.M., Batty, M., Barthélemy, M. (2011) 'Structure of Urban Movements: Polycentric Activity and Entangled Hierarchical Flows.' PLOS ONE 6, e15923. Available at: https://doi.org/10.1371/journal.pone.0015923 (Accessed: 15 September 2021)

Samuelsson, K., Chen, T.-H.K., Antonsen, S., Brandt, S.A., Sabel, C., Barthel, S. (2020) 'Residential environments across Denmark have become both denser and greener over 20 years.' Environmental Research Letters 16, 014022. Available at: https://doi.org/10.1088/17489326/abcf7a (Accessed: 15 September 2021)

Simpson, D., Gimmel, K., Lonka, A:, Grootens, J. (2018) Atlas Of the Copenhagens, 1st ed. Ruby Press: Berlin.

Teller, J. (2021) 'Urban density and Covid-19: towards an adaptive approach.' Buildings and Cities 2 (1), 150-165. Available at: https://doi.org/10.5334/bc.89. (Accessed: 15 September 2021)

Wang, H., Yang, Y. (2019) 'Neighbourhood walkability: A review and bibliometric analysis.' Cities 93, 43-61. Available at: https://doi.org/10.1016/j.cities.2019.04.015 (Accessed: 15 September 2021)

Zhou, C., Su, F., Pei, T., Zhang, A., du, Y., Luo, B., Cao, Z., Wang, J., Yuan, W., Zhu, Y., Song, C., Chen, J., Xu, J., Li, F., Ma, T., Jiang, L., Yan, F., Yi, J., Hu, Y., Xiao, H. (2020) COVID-19: Challenges to GIS with Big Data. Geography and Sustainability 1. Available at: https://doi.org/10.1016/j.geosus.2020.03.005 (Accessed: 15 September 2021) 